\title{
Engagement, Telepresence and Interactivity in Online Consumer Experience: Reconciling Scholastic and Managerial Perspectives
}

Anne Mollen and Hugh Wilson Cranfield School of Management, UK

Author for correspondence:

Hugh Wilson MA(Oxon) DipCompSci(Cantab) PhD(Cranfield)

Professor of Strategic Marketing

Cranfield School of Management

Cranfield, Bedford MK43 0AL, UK $+44(0) 1234751122$

hugh.wilson@cranfield.ac.uk www.cranfield.ac.uk/som 


\section{ENGAGEMENT, TELEPRESENCE AND INTERACTIVITY IN ONLINE CONSUMER EXPERIENCE: RECONCILING SCHOLASTIC AND MANAGERIAL PERSPECTIVES}

\section{ABSTRACT}

We propose a conceptual framework that reconciles the practitioners' view of engagement as central to online best practice and the scholarly view that tends to use other constructs to assess consumer experience. Building on research in e-learning as well as online marketing, we characterize the consumer experiential response to website and environmental stimuli as a dynamic, tiered perceptual spectrum which includes interactivity, telepresence and engagement. We construe engagement as a cognitive and affective commitment to an active relationship with the brand as personified by the website, and we propose dimensions of this construct. We discuss how the constructs of flow and involvement are related to but distinct from the constructs within our conceptual framework. We offer suggestions for future empirical research into developing a scale for engagement and assessing its importance and utility.

\section{KEYWORDS}

Engagement; telepresence; flow; interactivity; Internet; involvement 


\section{INTRODUCTION}

Marketers consider engagement to be the definitive umbrella term for online mechanisms that deliver competitive advantage to those employing them and contribute to the creation of "loyalty beyond reason" (Roberts, 2005). Practitioner definitions buttress this concept. The Advertising Research Foundation (Meskauskas, 2006) found that "Engagement is turning on a prospect to a brand idea enhanced by the surrounding context" and, more specifically, "engagement is a prospect's interaction with a marketing communication in a way that can be proven to be predictive of sales effects." The influential EConsultancy (2008) UK consumer engagement survey regards engagement to be the outcome of "repeated interactions that strengthen the emotional, psychological, or physical investment a customer has in a brand".

The academic world is less sanguine about the presumption that there is a causal relationship between engagement and sales. While numerous practitioner conferences on the subject attest to its centrality to online marketers' notion of best practice, the scholarly literature, until very recently, preferred to concentrate on the constructs of flow and interactivity, regarded as responsible "for greater favorability towards the product and the website" (Sicilia et al., 2005, p.31). Recent literature (Heath, 2007; Marci, 2006; Wang, 2006) acknowledges the ARF definition but largely uses that definition as a starting point, and neglects the relationship of engagement to other historic constructs dealing with consumers' online experience.

The semantic dissonance between the marketing and academic worlds is not mere pedantry. The online experience, where competitors are a mouse-click away and peer-to-peer communication subjects brands to forensic scrutiny, has to be skilful enough to sway an empowered, informed, and increasingly skeptical consumer (Urban, 2005). One of the primary mechanisms for constraining the deleterious effect of cost transparency online (Sinha, 2000) is the brand website, or company sponsored website. These websites are designed to "generate and reinforce positive brand and product messages, and have become a primary source of information for consumers whether they purchase onor offline" (Karson and Fisher, 2005, p.3). Yet, there is a common view that such brand sites, for the most part deprived of the 'cognitive lock-in' (Murray and Haubl, 2002) that can arise from 
transactional and service delivery, have little other than engagement in their armory. Accordingly, there is widespread practitioner acceptance that engagement is the critical online process by which brand equity is increased (Passikoff et al., 2007). Ninety percent of companies in the EConsultancy (2008) consumer engagement survey said that online customer engagement is either 'essential' or 'important' to their organisations. However, despite apparent corporate consensus, there has been little progress in the adoption of engagement as the most salient online metric. Many practitioners consider the ARF definition to be inoperable (Meskauskas, 2006). From a scholarly perspective, the construct's lack of linkage to flow, telepresence, and interactivity - constructs associated empirically with favorable attitudes to the brand and the website and with intention to purchase - impairs its claim of importance.

There is, then, a fault line between those practitioners who hold, a priori, that engagement is the 'holy grail' of online marketing, and scholars whose empirical work has tended to be focused elsewhere. The purpose of this article is to reconcile these perspectives. We establish a working definition of engagement as a discrete experiential property, independent of interactivity, flow, and telepresence. We present a conceptual framework that positions engagement along an experiential continuum, clarifying its relationship to interactivity, flow, and telepresence and to consumers' attitudinal and behavioral responses. Furthermore, by conceptualizing its dimensions, we seek to take the first steps towards the establishment of measures for the construct.

First, we outline our conceptual framework. Next, we discuss each stage of the consumer's experiential transition, deriving propositions on the key relationships between constructs. Finally, we discuss implications for theory and practice.

\section{OVERVIEW OF CONCEPTUAL FRAMEWORK}

The Stimulus-Organism-Response (S-O-R) model from environmental psychology, advocated by Eroglu et al. (2003) and refined by Sautter et al. (2004), provides an integrative framework for synthesizing existing research on website experience. The S-O-R model views consumer experience online as consisting of three components. The first is the website - its infrastructure and embedded 
mechanical stimuli - and its 'in situ' environment. The second is the consumer's internal state her/his experiential response to stimuli. This 'experience' may be more than an interaction with the mechanical features of the website and the properties of the environment: it can be a "holistic" response (Petre et al., 2006), a "website brand experience" (Ha and Perks, 2005), or an appreciation of the "brand as personified by the website" (Chang et al., 2003). The consumer's extant psychographic state may also temper this experiential response (Bart et al., 2005). Finally, this 'experiential brew' generates 'approach and avoidance' brand attitudes and behaviors (Eroglu et al., 2003; Sautter et al., 2004). We will use this theoretical framework (Figure 1) to frame our examination of the nature and role of consumer engagement.

\section{[Insert Figure 1 about here]}

We suggest that the consumer's experiential response can be characterized as a dynamic, tiered perceptual spectrum, ranging from perceived interactivity to telepresence (cognitive immersion in and perceived mastery of the heuristics of the medium and website) and finally, to engagement, a cognitive and affective commitment to the brand as personified by the website or other computermediated entities, which we suggest is an antecedent of attitudes and behaviors conducive to purchase or future purchase.

We will now review the literature pertinent to each model stage and derive associated propositions. A working definition of engagement emerges from the analysis.

\section{STIMULUS TAXONOMY}

Eroglu et al.'s (2003) study, using the S-O-R model, empirically validated that online atmospherics, defined as high (e.g. merchandise descriptions, price, terms of sale - critical to utilitarian objectives) and low (e.g. typestyles, animation, sounds - supporting hedonic goals) task relevant cues, affected consumers' internal states, and, consequently, shopping approach/avoidance behaviors. Sautter et al. (2004) added the "operator environment" and the specific properties of the online medium to the 'Stimulus' component of the S-O-R model: these properties were defined as vividness, interactivity, symbolism, and social elements. The experiential response to the operator 
environment of telepresence was incorporated into the 'internal states' component of the model (Sautter et al., 2004); we will return to the telepresence construct later. Sautter et al.'s (2004) refinement, by incorporating the interplay between the drivers embedded in the website and the properties of the operating environment, allows the introduction of the concept of tiered consumer response.

\section{PERCEIVED INTERACTIVITY}

There is no agreed definition of interactivity ( $\mathrm{Wu}, 2006)$, though most definitions assert the primacy of communication, regarding the process as two-way and characterized by the participant's sense of control. Most sources cite Steuer's (1992) definition as a starting point: "the extent to which users can participate in modifying the form and content of the mediated environment in real time". The studies differ in the perspectives through which interactivity is viewed.

The structuralist or mechanistic approach views interactivity as the response to the structural properties of the online medium or website, "the hardwired opportunity of interactivity provided during an interaction" (Liu and Shrum, 2002, p.55). Recent studies adopt a more explicitly experiential approach, arguing in favor of perceived interactivity (McMillan and Hwang, 2002), defined as "a psychological state experienced by a site user during his or her interaction with the website"(Wu, 2006, p.91), since it implicitly takes account of the cognitive processing and involvement in the activity. This conjecture better explains the empirical findings, noted by McMillan and Hwang (2002) and Song and Zinkhan (2008), that there is no relationship between the provision of interactive features embedded in a website and consumers' appreciation of interactivity and therefore, why, in certain cases, interactivity has a detrimental effect on consumer attitudes to websites, since it supports the notion that some consumers are resistant to levels of interactivity that make excessively onerous demands on cognitive processing (Liu and Shrum, 2005). A number of studies (McMillan and Hwang, 2002; Song and Zinkhan, 2008; Wu, 2006; Yadav and Varadajan, 2005) reach a degree of consensus on the core dimensions of perceived interactivity: perceived user control; two-way communication; and perceived responsiveness. 
Other empirical studies support interactivity's placement in the conceptual framework (Coyle and Thorson, 2001; Fiore et al., 2005; Hopkins et al., 2004; Klein, 2003) by positioning it as an antecedent of another experiential construct, telepresence, itself defined by Steuer (1992) as "the experience of presence in an environment by means of communication medium". We will re-examine this definition later. These studies do not all explicitly draw the distinction between structural interactivity and perceived interactivity. However, the operationalization of the interactivity construct in these studies, which unites the ability to manipulate the environment (Steuer, 1992) with representational richness (Hopkins et al., 2004) and personalization through virtual model technology (Fiore et al., 2005), indicates that they are implicitly measuring experiential response and the concomitant cognitive processing. We hence adopt the following definition and offer our first propositions:

Perceived interactivity is an experiential phenomenon that occurs when a user interacts with a website or other computer-mediated communication entities. Perceived interactivity is the degree to which the user perceives that the interaction or communication is two-way, controllable, and responsive to their actions.

Proposition 1: Perceived interactivity is the product of an exposure to a dual environment, that of the online medium in which the website is located and its specific properties, and the mechanics and heuristics of the website itself.

Proposition 2: Perceived interactivity is an antecedent of telepresence.

We will next consider telepresence in more detail, beginning with its relationship with the notion of flow.

\section{TELEPRESENCE}

Early work on online experience tended to focus on flow. Hoffman and Novak (1996) adapted Csikszentmihalyi's theory of flow, "the state in which people are so involved in an activity that nothing seems to matter" (Csikszentmihalyi, 1975, p.4, cited by Siekpe, 2005, p.3), to the computer mediated environment. They conceptualized flow as a "cognitive state experienced during navigation 
that is determined by (1) high levels of skill and control, (2) high levels of challenge, (3) focused attention and (4) is enhanced by interactivity and telepresence" (Novak et al., 2000, p.22).

However, while there is a body of empirical work emphasizing the centrality of flow to the online experience (Novak et al., 2000; Rettie, 2001) and advocating a causal relationship between flow and consumer attitudes to the website and the brand and purchase intention (Huang, 2006; Mathwick and Rigdon, 2004; Richard and Chandra, 2005), others suggest that the relationship of flow to anything commercially consequential remains to be established (Finneran and Zhang 2005; Zeithaml et al., 2002).

Both Koufaris (2002) and Siekpe (2005) qualify the case for the inclusion of flow in the model by noting the absence of conceptual standardization and the lack of consensus as to how flow is operationalized. While there is some phenomenological consensus as to what flow is "experientially" from a consumer's perspective (Pace, 2004; Rettie, 2001; Zwick and Dohlakia, 2006/7), an empiricist reservation remains that the concept of flow is a tribute to scholastic artifice: a construct that can only be tested and evaluated in terms of other assumed contributory latent constructs. Attempts to solve this methodological conundrum have met with mixed results. Koufaris's study (2002), despite its advocacy of parsimony in the use of components of the construct as a solution, is only partially successful in demonstrating a significant relationship between flow variables and unplanned purchases and intention to return to the site, and concludes by advising caution in the use of flow. Hausman and Siekpe (2009), using equal rigor in the selection of flow components, are able to uphold more forcefully the relationship between components of flow and commercially significant intentions.

Telepresence, which Steuer (1992) defines as "the experience of presence in an environment by means of communication medium", appears to be less contentious. Hoffman and Novak (1996) illustrated empirically a relationship between telepresence and exploratory behavior. Li et al. (2002), Fiore et al. (2005) and Suh and Chang (2006) demonstrated that telepresence serves as an intermediate variable between such website properties as virtual reality, image interactivity technology and 3D product advertising on the one hand, and consumer attitudes and behaviors on the 
other. Telepresence, thus, leads to consumers perceiving that they are more informed about a product, and therefore feel more positively about it (Suh and Chang, 2006). It also has a positive impact on the strength of beliefs and the intensity of attitudes towards a product (Klein, 2003). Fiore et al. (2005) viewed telepresence as an immersive response whereby consumers perceive the artificial environment to provide the necessary cognitive and sensory input equivalent to that of the more concrete real environment: this process positively affects instrumental and experiential value which, in turn, influences attitude to product, purchase intent and site patronage.

The operationalization of telepresence is less cohesive than the collective findings. While all start with Steuer's (1992) definition, the above empirical studies tend to adulterate the construct of telepresence with components associated with flow. Fiore et al. (2005) add the component of control, while Suh and Chang (2006) incorporate the dimensions of spatial presence ("being there"), "involvement and interest in the content of the displayed environment", and verisimilitude (naturalness; belief in the environment). We note that by aligning "involvement" with "interest in the content of the displayed environment", Suh and Chang (2006) are not employing "involvement" in the orthodox manner by implying interest in the brand and product category, but rather illustrating that the consumer displays focused attention or engrossment.

While there is justifiable concern that the relationship between flow and telepresence requires further investigation (Pace, 2003) given the somewhat free interpretation of telepresence in the above studies, there is sufficient evidence to suggest that telepresence amplified by some components of flow (broadly speaking, this equates to the construct of psychological immersion plus the constructs of control, skill and focused attention) does act as intermediate variable between website properties and consumer attitudes and behaviors. We synthesize these studies and incorporate evidence from computer studies literature (Slater, 1999; Witmer and Singer, 1998), which appears to take for granted the hybridization of certain flow and telepresence attributes, to formulate a definition of telepresence as follows: 
Telepresence is defined as the psychological state of 'being there' in a computer-mediated environment, augmented by focused attention. It is characterized by cognitive and sensory arousal, control, and immersion (defined as perceiving oneself to be steeped in and interacting with an environment that sustains a continuous stream of stimuli and experiences).

A compelling, immersive experience associated with telepresence appears helpful for establishing a positive attitude to a product or vendor. However, the evidence also shows that the experience of telepresence is not of itself enough to generate a relationship with a brand sufficient to induce purchase intention. In the studies considered here, only Fiore et al. (2005) has established a direct relationship between telepresence and attitude towards an online retailer, willingness to purchase and willingness to patronize. In contrast, Suh and Chang (2006) find no direct association between telepresence and purchase intention.

It is therefore reasonable to conjecture that telepresence might contribute to another experiential construct and that this construct, in turn, might directly influence optimal consumer attitudes and behaviors. Is there support for the notion that this construct is engagement?

\section{ENGAGEMENT}

\subsection{Telepresence as an antecedent of engagement}

Some literature, already discussed, supports the view that there is, in addition to perceived interactivity and telepresence, a third experiential state. Shih (1998), Mathwick and Rigdon (2004) and Fiore et al. (2005) interpose an intermediate variable between visitor immersion in the heuristics of the website, whether that psychological state is construed as flow or telepresence, and consumer attitudes and behavior. Shih $(1998$, p.660) defines that variable as bricolage, "the tinkering and manipulation of objects around one's immediate environment to develop and assimilate ideas", the mechanism by which consumers manage the vast array of information online and optimize the search and retrieval process. For Mathwick and Rigdon (2004), the bridge between flow and consumer attitudes and behavior is "perceived play", which has the two components enjoyment and escapism. Escapism is a state of psychological immersion, distinct from telepresence in that it represents 
"absorption in the online information search experience rather than in the perceived reality of virtual environments". Escapism is therefore an active state of cognitive processing rather than just a sense of 'being there'. Fiore et al. (2005) interpose instrumental and experiential value between telepresence and consumer attitudes. They define instrumental value as that which by the delivery of information assists goal-directed behavior, such as purchase decisions, and is acknowledged as such by the consumer, and experiential value as that which, during the consumption experience, offers "intrinsically satisfying pleasure to the senses, emotional satisfaction, mental play or amusement and fantasies" (Fiore et al., 2005, p.42).

These 'intermediate' constructs exhibit the dominant characteristics of "engagement" that are found in e-learning academic literature, marketing practitioner studies, and four papers (Heath, 2007; Marci, 2006; Rappaport, 2007; Wang, 2006) that appear to represent the first foray by marketing scholars into the engagement debate. These characteristics are active, sustained, cognitive processing, the attainment of relevance and utility, and emotional bonding, derived from pleasure and satisfaction. Table 1 expands on this research on engagement and closely related constructs to date.

\section{[Insert Table 1 about here]}

Given this congruence of characteristics, it seems plausible that engagement can stand as an intermediate variable between telepresence and consumer attitudes and behavior. The e-learning literature, in which engagement is better established, supports this causal chain. These studies, while paying little attention to the niceties of distinction between flow and telepresence, are adamant that engagement is a separate, experiential state. They distinguish this state by identifying defining characteristics that are consonant with those sustaining bricolage (Shih, 1998), perceived play (Mathwick et al., 2005) and instrumental and experiential value (Fiore et al., 2005). So, Jones (1998, p.211) asserts, "When an individual is in flow, they lose themselves. When an individual is engaged in a CBLE (Computer based learning environment) they are engaged in the process of learning". The former state is passive, the latter state active and motivated, representing the employment of cognitive strategies to expedite comprehension. Guthrie et al. (2004) stress that engagement represents a 
psychological state that goes beyond mere task fulfillment, and is characterized by involvement, being energized, being active, expending effort, and the full use of cognitive capability. Kearsley and Schneiderman (1998) concur: engagement is an activity that involves "active cognitive processes ... problem-solving, reasoning, decision-making and evaluation". They assert that engagement differs from simple interactivity because it must include creative, purposeful activity. Herrington et al. (2003) view online e-learning experience as a two-stage process in which the suspension of disbelief (flow/immersion) is a necessary precursor of engagement. They use the analogy of the cinema: "once the viewer has accepted the fundamental basis for the simulated world in which he or she is immersed, engagement with the story or the message of the film is entirely feasible". For film, read brand.

There is, then, at least a prima facie case that:

Proposition 3: Telepresence is an antecedent of engagement.

For this proposition to be meaningful, we need a definition of engagement, to which we will now turn.

\subsection{Defining engagement}

From a practitioner perspective, although there is an acknowledgement of the potency of engagement ("engagement trumps awareness", Rappaport, 2007) and of its experiential status ("engagement happens inside the consumer not the medium", Elliott, 2006), there is a clearer idea about what it does than what it is. The tension between a construct that is experientially defined but, to date, is only measured by practitioners via behavioral footprints that are assumed to be related, has not been resolved.

Although engagement remains an emergent rather than mature theme in academic literature, a number of extant definitions of the construct exist (see Table 1). For Rappaport (2007, p.138), engagement centers on "two key ideas: high relevance of brands to consumers and the development of an emotional connection between consumers and brands". For Douglas and Hargadon (2000), engagement is a "patina of cognitive activity" delivering an "extra-textual perspective". Heath 
(2007), in the advertising context, argues on the contrary for the primacy of emotion, viewing engagement as a "subconscious emotional construct" expressed as "the amount of "feeling' going on when an advertisement is processed". He suggests that therefore the relationship between attention (defined as conscious thinking) and engagement is asymmetric and, in some instances, non-existent. Marci (2006, p.383) defines engagement in neuro-physiological terms as "the combination of audience synchrony (attention) plus intensity (emotional impact)", where synchrony is defined as "the degree to which an audience's physiological state uniformly changes when exposed to a media stimulus" and intensity is defined as "the cumulative strength of physiological response to a media stimulus".

While no definition has become the benchmark, there are three insistent themes. First, engagement is a mental state that is accompanied by active and sustained, even complex, cognitive processing (Douglas and Hargadon, 2000, 2001; Guthrie et al, 2004; Herrington et al., 2003; Jones, 1998; Kearsley and Schneidermann, 1999; Marci, 2006; Mathwick and Rigdon, 2004; Shih, 1998). Second, engagement is associated with the satisficing of utility and relevance (Fiore et al., 2005; Rappaport, 2007; Wang, 2006). Third, engagement involves emotional bonding or impact (Heath, 2007; Marci, 2006; Rappaport, 2007; Wang, 2006), emotional congruence (Douglas and Hargadon, 2000, 2001) and pleasure and satisfaction (Fiore et al., 2005; Mathwick and Rigdon, 2004).

If we can begin to ascertain what engagement $i s$, then we must also elucidate what engagement is not. Specifically, we should clarify the relationship of engagement to the construct of involvement. As our earlier discussion points out, 'involvement' as a component of telepresence is merely a synonym for focused attention or 'engrossment' in the website. However, as Table 1 indicates, 'involvement', in the more academically orthodox sense, is an important dimension of engagement. Indeed, the semantic blurring between involvement, as it is conventionally operationalized in the sense of "importance and relevance to me" (Bienstock and Stafford, 2006), and instrumental value (utility and relevance), which is directly associated with engagement (Rappaport, 2007; Wang, 2006), is the marker for the conceptual convergence between the e-learning and marketing fields dealing with engagement. 
Nevertheless, there are three distinctions between engagement and involvement, which Thomson et al. (2005) define as "a state of mental readiness that typically influences the allocation of cognitive resources to a consumption object, decision, or action". The first is that consumer involvement hence requires a consumption object which is usually defined as a product category (Goldsmith and Emmert, 1991) whereas, in our paper, the consumption object is the 'brand personified by the website'. Second, engagement goes beyond involvement in encompassing an active relationship with the brand as personified by the website: the intention to act trumps the involvement construct's more passive allocation of mental resource. Third, engagement requires more than the exercise of cognition: it requires the satisficing of experiential value as well as that of instrumental value - the latter is more commonly associated with involvement. A caveat is that some measures of involvement, despite Thomson et al.'s (2005) emphasis on the cognitive aspect, contain affective components (Zaichkowsky, 1985). Yet there remains a substantive difference of degree: those measures remain more indicative of the 'pleasurably diverting' rather than expressions of a commitment to pursue an active relationship with a brand.

Accordingly, we define online engagement as follows.

Online engagement is a cognitive and affective commitment to an active relationship with the brand as personified by the website or other computer-mediated entities designed to communicate brand value. It is characterized by the dimensions of dynamic and sustained cognitive processing and the satisficing of instrumental value (utility and relevance) and experiential value (emotional congruence with the narrative schema encountered in computer-mediated entities).

We will explain our use of the term 'congruence'. Much of the e-learning work on immersion and engagement uses the lens of schema theory. Douglas and Hargadon (2001, p.154) define schemas as "the building blocks of information processing, a cognitive framework that determines what we know about the world, the objects it contains, the tasks we perform within it, even what we see". Scripts are a sub-set of schemas: a scene within a schema, calling up a series of tasks and actions appropriate to the context. In the context of a brand narrative, we view the online environment as a 
vast information store, wherein brands strive, through their arrangement and projection of information, to generate a dynamic, pleasurable state in consumers. This state, a prerequisite for successful imprinting, arises from cognitive access to a wide range of scripts and schemas, both inherent in the brand communication and derived from the consumers' own cognitive and affective framework (Douglas and Hargadon, 2001, p.156). The resultant tension between internal and external scripts and schemas generates a pleasurable cognitive and affective dissonance, which in its drive to find utility and emotional congruence with the "whole" of the educational message or narrative or brand, disrupts the immersive, mechanical, experience.

We therefore believe that congruence is an inalienable part of the engagement process. While practitioners might prefer 'emotional bonding' to frame an enduring relationship between consumer and brand, we believe that congruence is more apt if one refers to a wide range of consumer products, from high to low product category involvement. It is possible to be 'bonded' with a Harley Davidson; that is less likely to be the case with a washing powder, although, in the latter case, the idea of emotional resonance, correspondence, or 'congruence' with the brand ethos can be valid and lasting.

\subsection{Engagement and its relationship to optimal consumer attitudes and behaviors}

We have mentioned that the frailty of the ARF definition has led to practitioners equating engagement with behavioral footprints. Many practitioners challenge this reliance on behavioral measures (generally based on time spent, pages called up and duration and recency of web site visits) as a retreat to an unsatisfactory comfort zone (Dykes, 2008). The scant empirical academic marketing literature on engagement has equally not resolved the issue of associating engagement with optimal consumer outcomes. Wang's (2006) advertising study provides empirical validation of the relationship between engagement, initiated by contextual relevance, and consumer attitudes to brand communication, but limits measurement to a single item. Marci's (2006) study shows empirically that context is a driver of engagement but restricts its scope to the measurement of engagement and its effects through the observation of physiological correlates.

There is, then, limited empirical support for a direct relationship between engagement and optimal consumer attitudes and behaviors. Yet, it is both plausible and consistent with the available 
data that this relationship exists. Empirical investigation of this relationship should not only incorporate the development of a multi-item scale reflecting the construct's multidimensionality, but also consider triangulation with physiological and neural correlates, following the work of Marci (2006) and Fugate (2008). Hence:

Proposition 4: There is a relationship between online engagement and optimal consumer attitudes and behaviors.

\section{DISCUSSION}

\subsection{Implications for theory and practice}

Our paper responds to calls to investigate online "experiential intensity" (Demangeot and Broderick, 2006), and provides a template to complement structural and behavioral measures with experiential metrics that may offer a more efficient way of tracking consumer relationships with brands and allow marketers to devise more effective structural mechanisms for a durable emotional connection (Du Plessis, 2007). We supplant a loose and operationally limited practitioner definition but, in doing so, we refute the assertion that engagement (as practitioners understand it) is simply a mistranslation of more familiar academic terms. Engagement is not a proxy for flow, telepresence, or interactivity; rather, it is a discrete construct, characterized by specific experiential components - a construct that can also be reconciled with extant academic work. This reconciliation arises partly from identifying lacunae in existing academic studies and partly through a synthesis of an eclectic body of literature that supports the adoption of a third experiential construct. We now have a theoretical bridge between the practitioner and scholastic worlds.

By enabling a common discourse, empirical investigations into experiential metrics and website structural mechanisms in a quest for improved emotional congruence between consumer and brand can now proceed in a manner that directly aligns with practitioner framing of the issue. Our framework also nudges the practitioner away from a default behavioralist position, offering the prospect of an experiential tool-kit to complement existing metrics, thereby enabling a more efficient and productive allocation of resource. 


\subsection{Future research directions}

We have argued that engagement is a sustainable intermediate variable between the website drivers of consumer experience and commercial desirable consumer attitudes and behaviors. Research is now needed into this proposition's ontological adequacy.

We must also acknowledge that our framework is only a 'best fit' conjecture. There is an inherent frailty in any structured approach to consumer experiential states (Zwick and Dholakia, 2006/7). The process by which perceived interactivity gives way to telepresence, which in turn gives way to engagement, is unlikely to be so comfortably linear; nor can one implicitly assume, as does our diagram (Figure 1), that the consumer is a 'tabula rasa' in relation to the website and/or brand. We can envisage at least three other potential scenarios:

(a) Online engagement can exist independently of telepresence. Online engagement, as we define it, must incorporate the satisfying of instrumental value (utility and relevance) and experiential value (emotional congruence). A website stimulus other than telepresence may generate that experiential state.

(b) The relationship between telepresence and engagement may have an element of reciprocity. If a consumer is highly involved with a brand or product category prior to the website encounter, whether due to engagement generated by a previous encounter or due to other contacts with the brand or product category, he/she may be pre-disposed to spend time on and interact with the site and by doing so contribute to telepresence.

(c) Telepresence may not automatically lead to engagement. This is, indeed, a corollary of our definitions, which however we point out for clarity: engagement will not occur, no matter how stimulating or immersive the website experience, if the site fails to be relevant and of use to the consumer and hence to evoke some form of cognitive and affective commitment.

Suggested next steps for researchers include the development of an engagement scale to allow the testing of the conceptual framework and the associated propositions. It is incumbent on such a venture that it rigorously tests the assertion "engagement trumps awareness" (Rappaport, 2007) - 
another construct with well-established links to consumer choice (Macdonald and Sharp, 2000).

Researchers may wish to investigate to what degree engagement can be moderated by factors such as the experiential quality and narrative drive of the website or other computer-mediated entity, the collaborative experience of peer to peer interaction (Schembri, 2009), and the individual's own innate attitudinal and behavioral disposition. Given the evidence of the neuro-marketing field, which emphasizes the pre-eminence of emotion in decision-making and brand affiliation (Du Plessis, 2007), exploring the relationship and relative valence between cognitive and affective components of the engagement construct may also be fruitful.

We accept that our conceptual framework may raise as many questions as it answers, but we hope that by seeking to provide a conceptual and semantic bridge between different perspectives we have aided academic and practitioner collaboration in the development of viable measures for the engagement construct and in the assessment of its importance and utility.

\section{REFERENCES}

Bart Y, Shankar V, Sultan F, Urban GL. Are the drivers and role of online trust the same for all web sites and consumers? A large-scale exploratory empirical study. J Mark 2005;69(4):133-152.

Bienstock CC, Stafford MR. Measuring involvement with the service: a further investigation of scale validity and dimensionality. J Market Theor Pract 2006;14(3):209-221.

Chang CJ, Tekchandaney JR, Rangaswamy A, Simpson TW. Websites as personalities and playgrounds: their effects on brand image. Working Paper, eBusiness Research Center, Pennsylvania State University, PA, 2003.

Coyle JR, Thorson E. The effects of progressive levels of interactivity and vividness in web marketing sites. J Advert 2001;30(3):65-77.

Demangeot C, Broderick AJ. Exploring the experiential intensity of online shopping environments. Qual Market Res Int J 2006;9(4):325-351.

Douglas JY, Hargadon A. The pleasures of immersion and engagement: schemas, scripts and the fifth business. Digit Creativ 2001;12(3):153-166.

Douglas JY, Hargadon A. The pleasure principle: immersion, engagement, flow. Proc. 11th ACM on Hypertext and Hypermedia 2000:153-160.

Du Plessis E. A view on the prospects for neurological research and advertising engagement and effectiveness. Int J Advert 2007;26(1):129-132.

Dykes B. The truth about engagement. iMedia Connection, 28 May 2008. http://www.imediaconnection.com/printpage/printpage. $\operatorname{aspx}$ ?id=19465

Elliott S. The new rules of engagement. New York Times, March 21, 2006.

Eroglu SA, Machleit KA, Davis LM. Empirical testing of a model of online store atmospherics and shopper responses. Psychol Market 2003;20(2):139-150.

EConsultancy. Online Customer $\quad$ Engagement Report 2008. http://econsultancy.com/reports/online-customer-engagement-report-2008

Finneran CM, Zhang P. Flow in computer mediated environments: promises and challenges. Comm Assoc Inform Syst 2005;15:82-101.

Fiore AM, Jihyun K, Hyun-Hwa L. Effect of image interactivity technology on consumer responses 
toward the online retailer. J Interact Market 2005;19(3):38-53.

Fugate DL. Marketing services more effectively with neuromarketing research: a look into the future. J Serv Market 2008;22(2):170.

Goldsmith RE, Emmert J. Measuring product category involvement: a multitrait-multimethod study. J Bus Res 1991;23(4):363-371.

Guthrie JT, Wigfield A, Barbosa P, Perencevich KC, Taboada A, Davis MH, Scafiddi N, Tons S. Increasing reading comprehension and engagement through concept-oriented reading instruction. J Educ Psychol 2004;96(3):403-423.

Ha HY, Perks H. Effects of consumer perceptions of brand experience on the web: brand familiarity, satisfaction and brand trust. J Consum Behav 2005;4(6):438-452.

Hausman AV, Siekpe JS. The effect of web interface features on consumer online purchase intentions. J Bus Res 2009; 62:5-13.

Heath R. How do we predict advertising attention and engagement? School of Management University of Bath Working Paper, 2007(9).

Herrington J, Oliver R, Reeves TC. Patterns of engagement in authentic online learning environments. Aust J Educ Tech 2003;19(1):59-71.

Hoffman DL, Novak TP. Marketing in hypermedia computer-mediated environments: conceptual foundations. J Mark 1996;60(July):50-68.

Hopkins CD, Raymond MA, Mitra A. Consumer responses to perceived telepresence in the online advertising environment: the moderating role of involvement. Market Theor 2004;4:137-162.

Huang M-H. Flow, enduring, and situational involvement in the Web environment: a tripartite second-order examination. Psychol Market 2006;23(5):383-411.

Jones MG. Creating electronic learning environments: games, flow, and the user interface. Proc. Association for Educational Communications and Technology 1998.

Karson EJ, Fisher RJ. Predicting intentions to return to the web site: Extending the dual mediation hypothesis. J Interact Market 2005;19(3):2-14.

KearsleyG G, Schneiderman B. Engagement theory: a framework for technology-based teaching and learning. Educ Tech 1998;38(5):20-23.

Klein LR. Creating virtual product experiences: the role of telepresence. J Interact Market 2003;17(1):41-55.

Koufaris M. Applying the technology acceptance model and flow theory to online consumer behavior. Inform Syst Res 2002;13(2):205-223.

Li H, Daugherty T, Biocca F. Impact of 3-D advertising on product knowledge, brand attitude, and purchase intention: the mediating role of presence. J Advert 2002;31(3):43-57.

Liu Y, Shrum LJ. What is interactivity and is it always such a good thing? Implications of definition, person, and situation for the influence of interactivity on advertising effectiveness. J Advert 2002;31(4):53-64.

Macdonald, EK and Sharp, BM. Brand awareness effects on consumer decision making for a common, repeat purchase product: a replication. J Bus Res 2000;48:5-15.

Marci CD. A biologically based measure of emotional engagement: context matters. J Advert Res 2006;46:381.

Mathwick C, Rigdon E. Play, flow, and the online search experience. J Consum Res 2004;31:324.

McMillan SJ, Hwang J-S. Measures of perceived interactivity: an exploration of the role of direction of communication, user control, and time in shaping perceptions of interactivity. J Advert 2002;31(3):29-42.

Meskauskas J. Measure for measure: engagement. Media Post, May 1 2006; http://www.mediapost.com/

Murray KB., Haubl G. The fiction of no friction: a user skills approach to cognitive lock-in. Adv Consum Res 2002;29(1):11-18.

Novak TP, Hoffman DL, Yung Y-F. Measuring the customer experience in online environments: a structural modeling approach. Market Sci 2000;19(1):22.

Pace S. A grounded theory of the flow experiences of Web users. Int $\mathbf{J}$ Hum Comput Stud 2004;60(3):327-363.

Passikoff R, Keys B, Schultz DE. C-MEEs: cross-media engagement evaluations. ADMAP 2007;487:31. 
Petre M, Minocha S, Roberts D. Usability beyond the website: an empirically-grounded e-commerce evaluation instrument for the total customer experience. Behav Inform Tech 2006;25(2):189203.

Rappaport SD. Lessons from online practice: new advertising models. J Advert Res 2007;47(2):135.

Rettie R. An exploration of flow during Internet use. Internet Res 2001;11(2):103-113.

Richard M-O, Chandra R. A model of consumer web navigational behavior: conceptual development and application. J Bus Res 2005;58(8):1019-1029.

Roberts K. Lovemarks: The future beyond brands. PowerHouse;2005.

Sautter P, Hyman MR, Lukosius V. E-tail atmospherics: a critique of the literature and model extension. J Electron Commerce Res 2004;5(1):14-24.

Schembri S. Reframing brand experience: the experiential meaning of Harley-Davidson. J Bus Res 2009:in press.

Shih C-F. Conceptualizing consumer experiences in cyberspace. Eur J Market 1998;32(7/8):655-663.

Sicilia M, Ruiz S, Munuera JL. Effects of interactivity in a web site: the moderating effect of need for cognition. J Advert 2005;34(3):31-44.

Siekpe JS. An examination of the multidimensionality of flow construct in a computer-mediated environment. J Electron Commerce Res 2005;6(1):31-43.

Sinha I. Cost transparency: the net's real threat to prices and brands. Harv Bus Rev 2000;78(2):43-50.

Slater M. Measuring presence: a response to the Witmer and Singer presence questionnaire. Presence 1999;8(5):560-565.

Song JH, Zinkhan GM. Determinants of perceived web site interactivity. J Mark 2008;72(2):99-113.

Steuer J. Defining virtual reality: dimensions determining telepresence. J Comm 1992;42(4):73-93.

Suh K-S, Chang S. User interfaces and consumer perceptions of online stores: the role of telepresence. Behav Inform Tech 2006;25(2):99-113.

Thomson M, MacInnis DJ, Park CW. The ties that bind: measuring the strength of consumers' emotional attachments to brands. J Consum Psychol 2005;15(1):77-91.

Urban GL. Customer advocacy: a new era in marketing? J Publ Pol Market 2005;24(1):155-159.

Wang A. Ad engagement: a driver of message involvement on message effects. J Advert Res 2006;46:355-368.

Witmer BG, Singer MJ. Measuring presence in virtual environments: a presence questionnaire. Presence 1998;7(3):225-240.

Wu G. Conceptualizing and measuring the perceived interactivity of websites. J Current Issues Res Advert 2006;28(1):87-104.

Yadav MS, Varadarajan R. Interactivity in the electronic marketplace: an exposition of the concept and implications for research. J Acad Market Sci 2005;33(4):585-603.

Zaichkowsky JL. Measuring the involvement construct. J Consum Res 1985;12(3):341.

Zeithaml VA., Parasuraman A, Malhotra A. Service quality delivery through web sites: a critical review of extant knowledge. J Acad Market Sci 2002;30(4):362-375.

Zwick D, Dholakia N. Observing flow: a qualitative investigation of compelling web experiences and absorbing web environments. University of Rhode Island Working Paper 2006/7(2). 


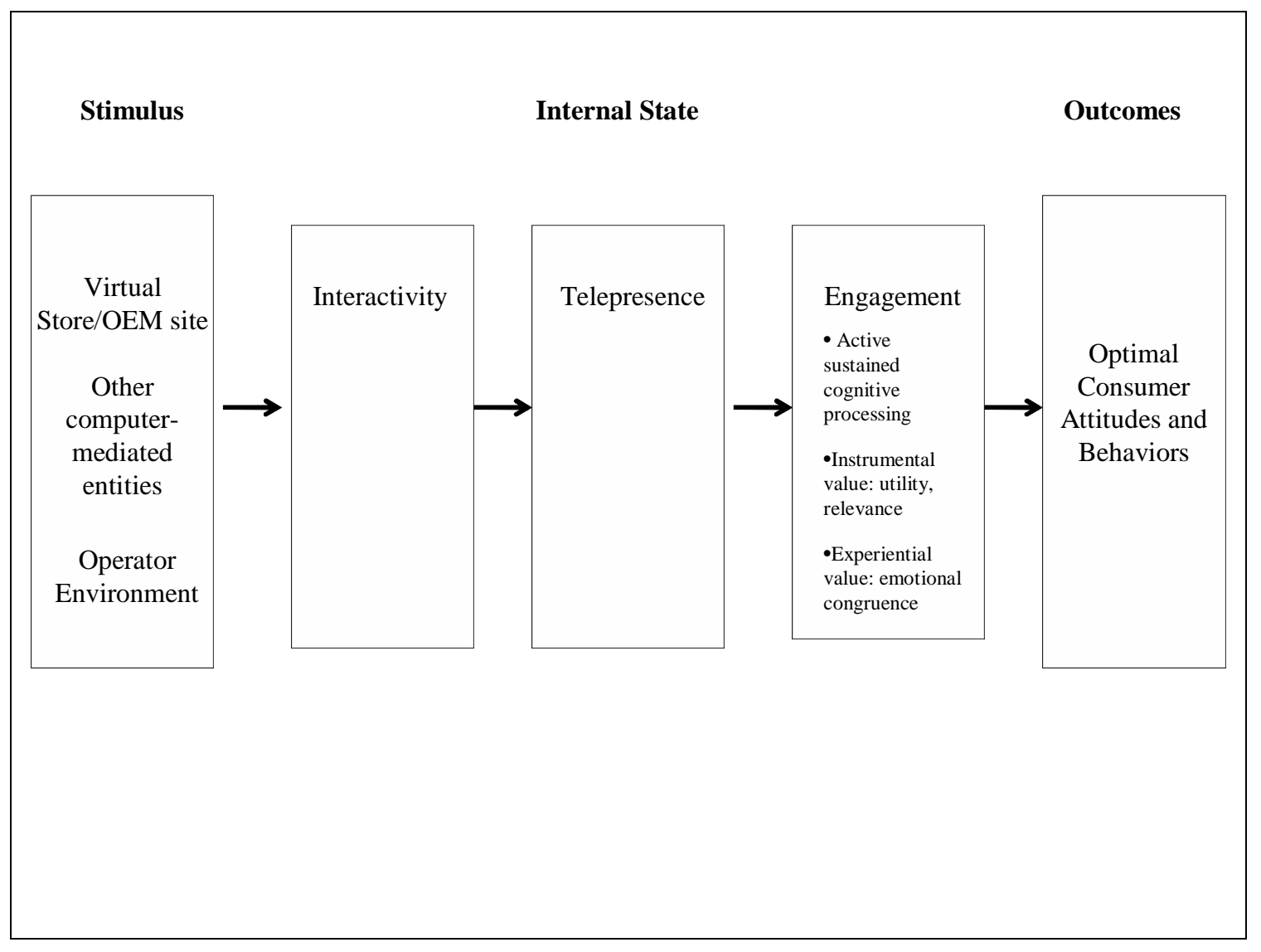

FIGURE 1: CONCEPTUAL FRAMEWORK 


\begin{tabular}{|c|c|c|c|c|}
\hline Construct & Definition & Dimensions & Context & Study \\
\hline Bricolage & $\begin{array}{l}\text { Bricolage: "the tinkering and manipulation of objects around one's immediate } \\
\text { environment to develop and assimilate ideas" }\end{array}$ & Cognitive processing facilitating learning. & $\begin{array}{l}\text { Consumer } \\
\text { behavior online }\end{array}$ & Shih (1998) \\
\hline Perceived Play & Highly positive experience delivering intrinsic value as escapism and enjoyment & $\begin{array}{l}\text { Pleasure; active cognitive processing; } \\
\text { psychological immersion in the information } \\
\text { search process. }\end{array}$ & Flow & $\begin{array}{l}\text { Mathwick and } \\
\text { Rigdon (2004) }\end{array}$ \\
\hline $\begin{array}{l}\text { Instrumental and } \\
\text { Experiential Value }\end{array}$ & $\begin{array}{l}\text { Value is "an interactive, relativistic, preference experience". Instrumental value is } \\
\text { the satisfying of goal-directed behavior through information delivery. Experiential } \\
\text { value is the satisfying of the senses, emotional satisfaction, mental play or } \\
\text { amusement, and fantasies }\end{array}$ & Utility/relevance; pleasure; satisfaction. & Interactivity & $\begin{array}{l}\text { Fiore, Kim and Lee } \\
\text { (2005) }\end{array}$ \\
\hline Engagement & $\begin{array}{l}\text { The nexus of intrinsic knowledge and/or interest and external stimuli that promotes } \\
\text { the initial interest in and desire to continue learning. }\end{array}$ & $\begin{array}{l}\text { Involvement (intrinsic and extrinsically } \\
\text { stimulated); learning (cognitive processing). }\end{array}$ & E-Learning & Jones (1998) \\
\hline Engagement & $\begin{array}{l}\text { Engagement theory encompasses the meaningful interaction (collaborative and } \\
\text { communicative) which results in active learning. }\end{array}$ & $\begin{array}{l}\text { Active cognitive processing; problem solving; } \\
\text { reasoning; decision-making; evaluation. }\end{array}$ & E-Learning & $\begin{array}{l}\text { Kearsley and } \\
\text { Schneiderman } \\
(1999)\end{array}$ \\
\hline Engagement & $\begin{array}{l}\text { "Engagement is what happens when we are able to give ourselves over to a } \\
\text { representational action. It involves a kind of complicity" }\end{array}$ & $\begin{array}{l}\text { Holistic involvement (suspension of disbelief); } \\
\text { cognitive processing. }\end{array}$ & E-Learning & $\begin{array}{l}\text { Herrington, Oliver } \\
\text { and Reeves (2003) }\end{array}$ \\
\hline Engagement & $\begin{array}{l}\text { No specific definition but engagement is central to cognitive categorization and } \\
\text { comprehension }\end{array}$ & $\begin{array}{l}\text { Interaction (motivated and strategic);complex, } \\
\text { sustained cognitive effort; concentration; active } \\
\text { learning. }\end{array}$ & E-Learning & Guthrie et al. (2004) \\
\hline Engagement & $\begin{array}{l}\text { Immersion in a work is the ideal affective experience; engagement is the cognitive } \\
\text { patina by which immersed individuals make sense of a narrative. }\end{array}$ & $\begin{array}{l}\text { Cognitive and affective dissonance leading to } \\
\text { congruence with narrative schema. }\end{array}$ & $\begin{array}{l}\text { Narrative and } \\
\text { Hypertext }\end{array}$ & $\begin{array}{l}\text { Douglas and } \\
\text { Hargadon } \\
(2000,2001)\end{array}$ \\
\hline Engagement & ARF definition & $\begin{array}{l}\text { Contextual relevance; utility; message } \\
\text { involvement; emotional bonding. }\end{array}$ & Advertising & Wang (2006) \\
\hline Engagement & $\begin{array}{l}\text { Engagement centres on the "high relevance of brands to consumers and the } \\
\text { development of an emotional connection between consumers and brands". }\end{array}$ & $\begin{array}{l}\text { Relevance; utility; involvement; emotive brand- } \\
\text { consumer contract. }\end{array}$ & Advertising & Rappaport (2007) \\
\hline Engagement & $\begin{array}{l}\text { The amount of subconscious feeling going on when an advertisement is being } \\
\text { processed. }\end{array}$ & $\begin{array}{l}\text { Behavioral: external measures e.g. eye tracking, } \\
\text { facial recognition, skin conductivity. } \\
\text { Measurement of cognitive and emotive power. }\end{array}$ & Advertising & Heath (2007) \\
\hline Engagement & $\begin{array}{l}\text { The combination of audience synchrony (attention) plus intensity (emotional } \\
\text { impact) }\end{array}$ & Physiological (bio) responses & $\begin{array}{l}\text { Neuro- } \\
\text { marketing }\end{array}$ & Marci (2006) \\
\hline
\end{tabular}

TABLE 1: LITERATURE ON ENGAGEMENT AND RELATED CONSTRUCTS 